\title{
MENEMUKAN KEMBALI PEMBARUAN PERKOTAAN BERBASIS PENGEMBANGAN MASYARAKAT: STUDI PENANGANAN PEMUKIMAN KUMUH DI PERKOTAAN INDONESIA
}

\author{
Reinventing Urban Renewal Based on Community Development: \\ Study of Slum Settlement in Indonesia's Urban Areas
}

Muhammad Taufiq ${ }^{1,2}$, Petrus Natalivan ${ }^{1}$, Suhirman $^{1}$, Benedictus Kombaitan ${ }^{1}$

Diterima: 16 Oktober 2018

Disetujui: 23 November 2018

\begin{abstract}
Abstrak: Konsep urban renewal menjadi salah satu pendekatan dalam kebijakan pengembangan kota yang mengedepankan optimalisasi profit di area perkotaan. Namun, hal ini dilakukan dengan menggerus pemukiman kumuh yang ada, dan berakhir dengan ketidakadilan di masyarakat. Untuk alasan ini, kebijakan pengembangan kota perlu mengarahkan implementasi urban renewal berbasis pengembangan masyarakat. Pertanyaan muncul apakah urban renewal perlu diberlakukan pada perkotaan di Indonesia, apakah urban renewal mendatangkan manfaat tertentu dalam mencapai pengembangan masyarakat yang lebih humanis dan apa batasannya. Artikel ini bertujuan memberikan pemahaman secara teoretis tentang pertimbangan dan implikasi penerapannya melalui ilustrasi studi kasus beberapa kota besar di Indonesia. Kajian ini mengevaluasi gagasan urban renewal dengan sudut pandang pengembangan masyarakat, melalui analisa deskripsi evaluatif dan literatur. Hasil kajian menunjukkan bahwa urban renewal perlu bagi perkotaan di Indonesia yang memprioritaskan kebijakan berorientasi menjadikan pusat kota sebagai area bisnis yang lebih kompetitif dan menghasilkan profit maksimal perkotaan melalui pemasukan pajaknya. Di sisi lain, hal ini dilakukan untuk memperindah wajah kota yang akan dengan sendirinya meningkatkan pengembangan komunitas yang berada di kota maupun suburban. Kearifan lokal dalam konteks pilihan basis kebijakan pengembangan kota menjadi batasan bagi optimalitas implementasinya.
\end{abstract}

Kata kunci: pembaruan perkotaan, pengembangan masyarakat, pemukiman kumuh, Indonesia

Abstract: Urban renewal concept is one of city development policies approaches. It promotes profit optimization in urban areas. However, this is done by eroding existing slums and ending with injustice for the community. For this reason, city development policies need to direct urban renewal implementation based on community development. The question arises whether urban renewal needs to be applied for urban areas in Indonesia, whether urban renewal brings certain

${ }^{1}$ Sekolah Arsitektur, Perencanaan dan Pengembangan Kebijakan, Institut Teknologi Bandung.

2 Pemerintah Kabupaten Langkat, Provinsi Sumatera Utara.

Korespondensi: taufiqlangkat@gmail.com/ @students.itb.ac.id 
benefits in achieving a more humane society development and its limits. This article aims to provide a theoretical understanding of the considerations and implications for its application through illustrative case studies from several major cities in Indonesia. This study evaluates urban renewal ideas from community development viewpoint, through descriptive, evaluative analysis and literature. Study results show that urban renewal is necessary for cities in Indonesia in term of policies that make city center become a more competitive business area and generate maximum urban profits through tax revenues. On the other hand, this is done to beautify city face which will automatically improve community development in cities and suburbs. Local wisdom in the context of a city's development policy choice base is a limitation for its implementation optimality.

Keywords: urban renewal, community development, slum settlements, Indonesia

\section{PENDAHULUAN}

Perencanaan kota melibatkan usaha berkelanjutan melalui pembaruan untuk meningkatkan pengembangannya. Salah satu tujuan perencanaan kota adalah pengembangan masyarakat atau komunitas yang ada di dalamnya. Umumnya basis perencanaan kota adalah peningkatan dalam tiga hal yakni ekonomi, sosial, dan lingkungan. Sinergitas ketiga hal ini menjadi pedoman dalam penekanan kebijakan perencanaan kota. Perencanaan kota dalam mendukung sektor ekonomi diantaranya dilakukan melalui fasilitasi pertumbuhan ekonomi seperti pertokoan, perkantoran, ritel dan perdagangan. Perencanaan kota dalam mendukung bidang sosial dilakukan melalui pemenuhan kebutuhan sosial diantaranya perumahan, taman, area rekreasi, pedistrian, dan fasilitas lain yang mendukung meningkatnya pengembangan masyarakat atau komunitas.

Adanya denyut nadi perekonomian di pusat kota berefek pada meningkatnya urbanisasi menuju area tersebut. Urbanisasi yang tidak terkendali menyebabkan timbulnya pemukiman liar yang cenderung kumuh dan berlokasi di pusat perkotaan. Hal ini berdampak pada kondisi kota yang semraut, tidak tertata, serta terdegredasi kapasitas fungsinya dalam mewujudkan pengembangan masyarakat. Kondisi tersebut juga mendatangkan inefisiensi pembangunan kota khususnya dalam mengoptimalkan fungsinya sebagai area berbasis sektor ekonomi, yakni perdagangan dan jasa. Dengan demikian, penanganan pemukiman kumuh di pusat kota menjadi tantangan tersendiri dalam perencanaan pengembangan kota. Tuntutan perkembangan kota akan arah kemajuannya di masa mendatang menjadi hal yang dihadapi dalam menentukan kebijakan perencanaannya. Urban renewal atau pembaruan perkotaan sebagai salah satu kebijakan pengembangan kota mengedepankan profit perkotaan dari geliat perdagangan dan jasa yang terjadi di kota.

Perumahan sebagai salah satu fokus dalam perencanaan kota. Kebijakan pengembangan kota perlu memperhatikan penanganan perumahan penduduk kota, disamping secara bersamaan meningkatkan fungsinya sebagai area penyelenggara perdagangan dan jasa. Salah satu hal yang dihadapi dalam penerapannya adalah mengintegrasikan urban renewal (pembaruan kota) dengan penanganan pemukiman kumuh untuk meningkatkan pengembangan masyarakat di perkotaan. Pembaharuan perkotaan dapat dipahami sebagai pendekatan dalam peruntukan kembali land use untuk meningkatkan kualitas lingkungan, melalui kebijakan dalam perbaikan isu-isu perkotaan khususnya dalam sosial, ekonomi dan lingkungan, serta meningkatkan jaringan sosial yang ada untuk mewujudkan pengembangan masyarakat, disamping itu juga memberikan manfaat di berbagai multi level stakeholder (Adams \& Hastings, 2001; Chan \& Yung, 2004; Lee \& Chan, 2008; Wang, Li, Zhang, Li, \& Asare, 2017). Di sisi lain, adanya kebutuhan dan rekomendasi arah penelitian urban renewal yang berkelanjutan di masa depan berkenaan dengan penerapannya pada perspektif yang lebih komprehensif dan metode yang lebih obyektif (Zheng, Shen, \& Wang, 2014, hlm. 278) Pertanyaan muncul apakah urban renewal perlu diberlakukan pada perkotaan di Indonesia? Apakah urban renewal mendatangkan 
manfaat tertentu dalam mencapai pengembangan masyarakat yang lebih humanis dan apa batasannya?

Artikel ini mengevaluasi konsep urban renewal melalui sudut pandang pengembangan masyarakat dengan ilustrasi studi kasus beberapa kota besar di Indonesia. Seiring dengan meningkatnya pertumbuhan ekonomi di beberapa kota besar di Indonesia, hal ini serta merta meningkatkan arus urbanisasi menuju daerah tersebut. Urbanisasi yang melonjak ini tidak diiringi oleh pemenuhan tempat tinggal yang layak dan kemampuan masyarakat yang cukup untuk dapat tinggal di pusat kota. Dampak dari kondisi tersebut adalah meningkatnya pemukiman kumuh di beberapa kota besar di Indonesia seperti di kawasan Kali Ciliwung (Jakarta), Belawan (Sumatera Utara) Taman Sari (Bandung), Boezem Morokembagan (Surabaya) dan Tallo (Makasar) (Ariyanti, 2013; Zul \& Ang, 2013). Kondisi ini mempengaruhi kebijakan pengembangan kota yang mana semestinya fokus pada fungsi perkotaan menjadi fokus pada fungsi lain, seperti penanganan pemukiman kumuh. Berkenaan hal tersebut, diperlukan adanya tinjauan teoretis akan pentingnya penerapan konsep urban renewal di perkotaan Indonesia.

\section{METODE}

Kajian penelitian ini dilakukan melalui deskriptif, analisis evaluatif dan literatur. Artikel ini mengkombinasikan konsep urban renewal dengan pengembangan masyarakat di perkotaan. Selanjutnya memberikan pemahaman teoretis melalui perdebatan teoritik dan fakta - fakta empiris, serta mereview realitasnya melalui pandangan penulis sebagai bentuk deskripsi eksplorasi konklusif. Pengumpulan data sekunder pada kajian ini berupa jurnal internasional, buku literatur, dan data dari kementerian terkait. Fokus kajian yang diamati antara lain:

1. Konsep Urban renewal.

2. Aspek probabilitas penerapan UR di Indonesia berkenaan pengembangan komunitas di perkotaan.

3. Perdebatan teori, fakta empiris dan diskusi.

\section{HASIL}

\section{Urban renewal, penafsirannya dalam konteks Indonesia}

Urban renewal (UR) adalah bentuk pembaharuan perkotaan yang bersifat instruktif karena mengilustrasikan betapa sulitnya merumuskan kebijakan yang bebas dari efek samping, kebijakan ini bertujuan menghilangkan perumahan dibawah standar, revitalisasi ekonomi kota, membengun perubahan yang baik dan mengurangi segregasi di perkotaan (Levy, 2016, hlm. 209). UR umumya dikenal sebagai kebijakan pengembangan perkotaan di Amerika Serikat yang dimulai pada tahun 1949 pasca perang dunia ke dua. Kebijakan ini adalah amandemen dari kebijakan national housing act tahun 1937. Awal mulanya housing act 1937 melayani pemenuhan perumahan layak huni bagi penduduk berpenghasilan menengah melalui konsep pembangunan perumahan yang berada di area suburban. Program ini bekerjasama dengan pihak swasta dalam pemenuhan perumahan tersebut. Pemerintah mengalihkan konsentrasi pemukiman warga yang berada di pusat kota (seperti New York) menuju ke area suburban (seperti St. Louis, Missouri). Penduduk dengan penghasilan menengah diharapkan mampu menjalankan program ini dan tidak berdampak signifikan bagi kehidupannya. Jarak yang jauh antara lokasi tempat tinggal dan lokasi kerja dapat ditutupi oleh penduduk berpenghasilan menengah dengan cara mengalokasikan pengeluarannya melalui pengadaan alat transportasi pribadi seperti mobil.

Di tahun 1949, undang-undang housing act melalui klausul UR yang terkandung didalamnya mengakomodasi kepentingan penduduk berpenghasilan rendah melalui 
pemenuhan fasilitas perumahan layak huni yang berlokasi di suburban. Umumnya mereka tinggal di perkotaan dengan mendiami pemukiman kumuh. Sebagai contoh, beberapa perumahan yang berbentuk bangunan blok bertingkat di New York (west 99 th street dan west $98^{\text {th }}$ street) di hancurkan dan dipindah ke area suburban melalui bangunan Pruitt-Igoe (St. Louis, Missouri), sejenis apartemen yang dialokasikan bagi penduduk berpenghasilan rendah pindahan dari pusat kota.

Program ini mengakomodasi pemenuhan perumahan layak huni bagi masyarakat slum area yang berada di pusat kota dan bagi sebagian besar prajurit yang pulang dari medan perang pasca perang dunia kedua. Hal ini dilakukan melalui pembangunan sebanyak 8.100 unit rumah untuk komunitas berpenghasilan rendah pada periode 6 tahun pertamanya. Perumahan tersebut membutuhkan anggaran per tahunnya sebesar \$308 juta untuk alokasikan tempat tinggal 3,5 juta penduduk.

UR adalah perencanaan ulang pusat kota menjadi lebih menarik dengan tujuan meningkatkan pajak yang lebih tinggi dan profit sektor ekonomi perkotaan (lihat gambar 1). Pemukiman kumuh (slum area) yang berada di sekitaran pusat kota ditafsirkan sebagai penghalang UR. Kebijakan ini berlanjut melalui penertiban terhadap pemukiman kumuh tersebut. Tahun 1956 timbul usulan agar kota memiliki program komprehensif dalam pembersihan slum area, kebijakan ini diikuti secara serentak oleh seluruh pemerintah lokal negara bagian Amerika Serikat.

Implementasi kebijakan tersebut menghasilkan kondisi pusat kota yang sepenuhnya mengakomodir penggunaan lahan (land use) perkotaan berorientasi perdagangan dan jasa, serta pemukiman yang umumnya merupakan pemukiman apartemen mewah dengan sewa tinggi. Program ini menyisakan tragedi kemanusiaan, sebagai contoh, pembersihan hunian mayoritas panduduk berkulit hitam di west 99th street dan west 98th street New York (berdampak pada tiga ratus ribu keluarga). Pada tahun 1949, Presiden Harry Truman menandatangani Undang-undang Perumahan, yang memberi mandat pemerintah federal, negara bagian, dan pemerintah lokal dalam penanganan perumahan warga yang belum pernah terjadi sebelumnya. Salah satu inisiatif utama undang-undang perumahan melalui kebijakan UR adalah menghancurkan sekitar dua ribu komunitas pada 1950-an dan 1960an. Di sisi lain, memaksa lebih dari 300.000 keluarga keluar dari rumah mereka. Secara keseluruhan, sekitar separuh dari korban UR berkulit hitam, suatu kenyataan yang mengarah pada sindiran James Baldwin yang terkenal bahwa "pembaruan perkotaan berarti penghapusan Negro" (Reason TV, 2011). Di sisi lain, UR juga berimplikasi pada pembaruan wajah kota yang lebih tertata melalui pembangunan sarana dan prasarana sosial yang lebih layak seperti renovasi taman kota, pelataran pinggiran sungai, dan fasilitas publik lainnya di pusat kota.

Berkaca pada pengalaman Amerika Serikat dalam menangani perencanaan pengembangan perkotaannya, maka apakah ini merupakan suatu konsep yang dapat diadopsi pada kota-kota besar di Indonesia, ataukah ini hanya berlaku di negara itu saja. Menimbang kondisi negara kita dimana peningkatan populasi seiring dengan peningkatan urbanisasi menuju kota-kota besar yang ada, mengindikasikan bahwa laju pertumbuhan penduduk, khususnya penduduk usia produktif cenderung berkonsentrasi di kota. Dengan proyeksi ini, lambat laun kota-kota besar di Indonesia akan menghadapi situasi yang sama dengan apa yang telah dihadapi oleh kota-kota besar di Amerika Serikat.

Permasalahannya adalah bagi penduduk berpenghasilan menengah bisa saja memilih lokasi tempat tinggal di luar pusat kota (suburban) karena memiliki biaya transportasi antar lokasi tempat tinggal dan tempat bekerja (melalui kendaraan pribadi atau transportasi umum). Demikian pula dengan penduduk berpenghasilan tinggi yang memiliki lebih banyak pilihan, dapat berdomisili di pusat kota dengan menyewa atau memiliki apartemen/ real estate di pusat kota atau bertempat tinggal di suburban. Namun, bagi penduduk berpenghasilan rendah, maka akan tetap mendiami lokasi yang berdekatan 
dengan pusat kota dengan fasilitas seadanya dan cenderung merupakan alih fungsi lahan atau tanah negara dengan kepemilikan yang tidak permanen. Atau dengan kata lain, bagi masyarakat berpenghasilan menengah ke atas, konsep urban renewal dapat diatasi dengan meninggalkan pusat kota dan bermukim di suburban (urban sprawl). Namun, bagi masyarakat berpenghasilan rendah, hal ini tidak berlaku sehingga tetap menempati slum area karena tidak memiliki kemampuan mobilisasi. Kondisi ini menyebabkan tidak terjadinya urban sprawl dalam konteks masyarakat berpenghasilan rendah.
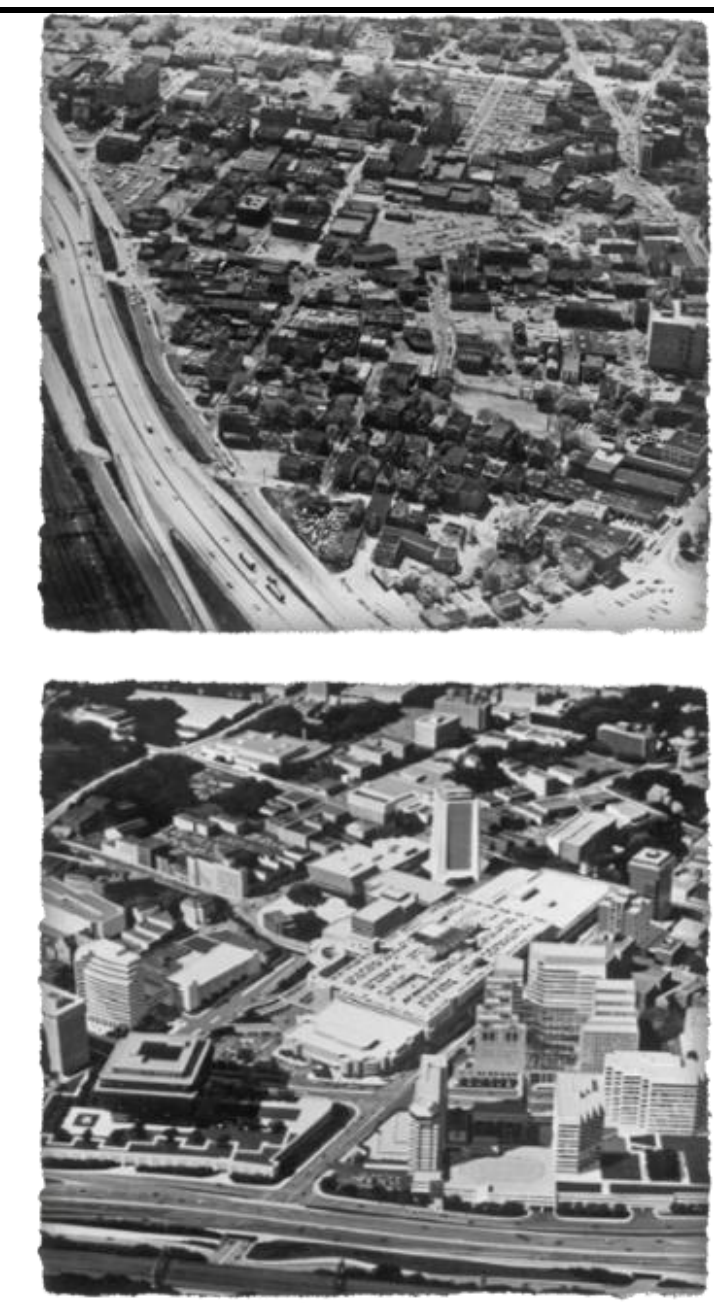

Sumber: Levy, 2016, p. 217

Pembaruan perkotaan di Stamford, Connecticut di tahun 1960 sebelum implementasi UR (atas) dan kondisi setalah dua dekade implementasinya (bawah)

\section{Gambar 1. Urban renewa/di Stamford, Connecticut, USA}

UR adalah suatu kebutuhan, bukan ancaman. Optimalitas fungsi perkotaan perlu didukung oleh penggunaan land use yang sesuai peruntukannnya. Penanganan pemukiman kumuh adalah agenda tersendiri bagi kota-kota besar di Indonesia. Kondisi ini perlu ditangani dengan cepat dan tidak menunggu klimaks terjadinya kerugian yang lebih besar. Dengan segera menangani pemukiman kumuh, maka pemerintah kota dengan sendirinya telah menghemat anggarannya. Karena semakin lama penanganan dilakukan, akan semakin tinggi biaya yang akan diperlukan di masa yang akan data. Hal ini ditengarai 
akibat dari semakin meningkatnya kuantitas pemukiman kumuh dan populasi warga yang mendiaminya. Semakin lama penanganan pemukiman kumuh maka semakin lama terciptanya optimalisasi incom yang bisa didapat dari perkotaan.
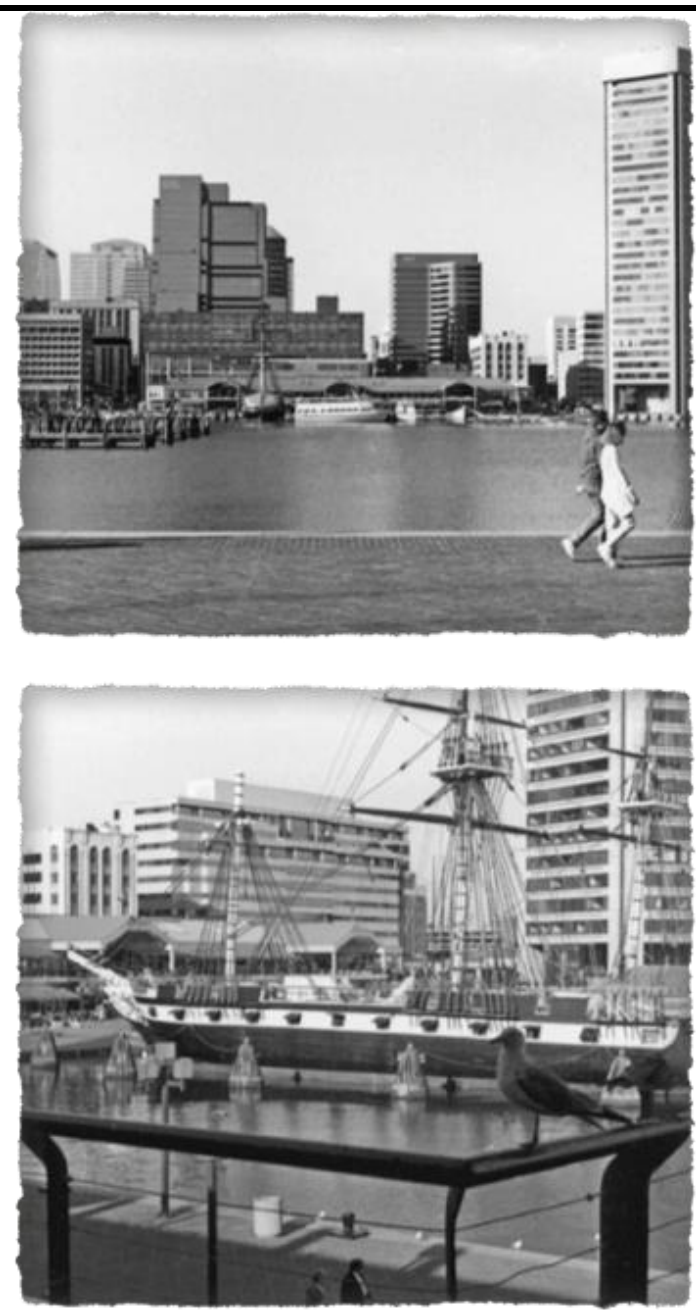

Sumber: (Levy, 2016, hlm. 216)

Pembangunan kembali pelataran pelabuhan Baltimore (atas), dilakukan bersama oleh kota dan Rouse Corporation. Pengembangan termasuk renovasi tempat-tempat wisata seperti USS Constellation (di bawah), restoran dan ritel, sejumlah besar ruang kantor, dan ratusan kamar hotel untuk mengakomodasi wisatawan dan pelancong bisnis.

\section{Gambar 1. Urban renewa/dalam mencapai pengembangan masyarakat di Pelabuhan Baltimore, USA}

Penanganan UR yang ideal akan cenderung mewujudkan pengembangan masyarakat. Hal ini umumnya dilakukan melalui pemenuhan fasilitas fisik perkotaan seperti taman kota, pedistrian, sarana-prasarana keluarga, hingga akhirnya membuat kota menjadi area senyaman dan seindah mungkin (lihat gambar 2). Anggapan bahwa slum area adalah penghalang UR tidak sepenuhnya benar. Hal ini lebih kepada prosedur dalam penanganan pengembangan kota, dimana slum area merupakan tantangan dalam implementasi UR. Penanganan slum area sebagai bagian dari kebijakan UR dimana maksud dan tujuannya adalah untuk menjadikan kota lebih humanis dengan mengembalikan fungsi land use kota dan menempatkan lokasi pemukiman warga menuju tempat yang lebih layak, seperti 
rumah susun atau rumah sederhana. Dengan demikian, penanganan tersebut telah mewujudkan pengembangan masyarakat yang lebih baik.

Peraturan housing act 1949 dilakukan melalui akuisisi kawasan kumuh dengan pendanaan cost sharing antara pemerintah negara bagian dan pemerintah pusat. Teknisnya adalah biaya akuisisi lahan sebanyak satu per tiga di tanggung pemeritah negara bagian dan dua per tiga ditanggung pemerintah pusat. UR lebih pantas dipahami sebagai tindakan atau proses dalam mengembalikan fungsi/ land use kota untuk mewujudkan pengembangan masyarakat. Untuk melaksanakannya, diperlukan adanya kerjasama antara pemerintah pusat dan pemerintah daerah, khususnya dalam mengakuisisi lahan-lahan di perkotaan dan membangunnya menjadi bangunan yang mendukung fungsi perkotaan agar meningkatkan pajak kota. Pembiaran pemukiman kumuh justru akan berdampak pada inefisiensi bagi incom perkotaan. Di sisi lain, penanganannya akan berdampak positif bagi kelangsungan hidup warga itu sendiri dan kelangsungan kota. UR memiliki dampak besar dalam meningkatkan pengembangan komunitas dan income perkotaan.

\section{Pemukiman kumuh, suatu eksternalitas bagi pertumbuhan di perkotaan Indonesia}

Permukiman kumuh adalah permukiman informal di daerah perkotaan, di mana orang mendapatkan layanan minimum karena mereka memiliki identitas informal, keamanan kepemilikan informal, dan tidak ada pengakuan formal oleh sektor publik (Alam \& Mondal, 2018; Wankhade, 2015). Di sisi lain, adanya kecenderungan anak-anak mengkonsumsi lebih sedikit daripada orang dewasa, itu sebabnya di rumah tangga kumuh emisi per kapita mereka menjadi lebih rendah (Adnan, Safeer, \& Rashid, 2018, hlm. 22). Pemukiman kumuh atau slum area umumnya adalah perumahan dengan kondisi kurang layak, kualitas hidup rendah, serta berlokasi pada area yang tidak pada peruntukannya. Kecenderungan slum area yang berada di pusat kota berdampak bagi minimnya kualitas pengembangan masyarakat di area tersebut. Hal ini juga sebagai alasan dikeluarkannya kebijakan UR, dengan tujuan agar masyarakat mendapat penghidupan yang lebih layak dan kota juga meningkat kualitasnya dalam penyediaan ruang perkotaan yang mendukung pengembangan komunitas dan fungsi utamanya dalam meraih profit area perkotaan. Slum area cenderung mendatangkan permasalahan bagi kota. Kondisinya yang kurang baik serta berada pada lokasi yang bukan peruntukannya berdampak pada berkurangnya optimalitas land use perkotaan sebagai penyedia aktifitas sektor perdagangan dan jasa. Kecenderungan meningkatnya perekonomian di perkotaan yang semakin meningkat dan disertai oleh meningkatnya kebutuhan akan bangunan-bangunan berorientasi profit, menggerus land use di perkotaan dan berdampak pada pertimbangan-pertimbangan yang lebih kompleks akan bangunan-bangunan yang ada di pusat kota. Perumahan yang dulu berada di pusat kota dan merupakan hal yang wajar, menemui kondisi dimana harus tergerus dengan adanya kepentingan land use perkotaan yagn semakin meningkat. Kondisi itu berdampak pada pemindahan perumahan yang ada di kota menuju suburban.

Karena tanah dan perumahan standar minimal, pada umumnya, tidak cukup cepat dipasok untuk memenuhi permintaan dari kelompok berpenghasilan rendah, jaminan ini dinyatakan secara dramatis melalui keberadaan daerah kumuh, liar, dan bentuk lain yang berkelanjutan (Montgomery, Stren, Cohen, \& Reed, 2013, hlm. 267). Belajar dari pengalaman urban renewal yang telah di lalui Amerika Serikat dan proyeksi kompleksitas permasalahan yang akan dialami kota-kota besar di Indonesia, hal ini mendatangkan adanya kecenderungan akan pertimbangan-pertimbangan dalam mengantisipasi perencanaan kota di masa mendatang. Tumbuhnya pemukiman kumuh sebagai akibat lambatnya penyediaan rumah bagi penduduk berpenghasilan rendah. Penghasilan warga yang rendah menyebabkan pemukiman kumuh minim dari layanan sosial dan infrastruktur yang layak. 
Kondisi pemukiman kumuh yang berada di pusat kota dengan sendirinya tidak mencerminkan pengembangan masyarakat secara spasial. Kriminalitas cenderung dapat berakibat dari keberadaan perumahan kumuh tersebut, dan bukan tidak mungkin korban dari tindak kriminal itu adalah penghuni slum area itu sendiri. Beberapa analisis baru-baru ini menunjukkan bahwa penghuni kawasan kumuh bukanlah ancaman bagi kota yang lebih besar, tetapi mereka sendiri adalah korban kejahatan perkotaan dan kekerasan tersebut, yang sering kali diselenggarakan dari luar daerah kumuh (LeGates \& Stout, 2015, hlm. 367). Dengan demikian adanya kecenderungan bahwa kualitas lingkungan juga berdampak pada rentannya daerah dersebut sebagai korban tindak kriminalitas. Kekerasan dan kejahatan dapat dipicu oleh lingkungan yang kurang layak dan menjadikannya sebagai sasaran. Dari sudut pandang ini, maka pengendalian pemukiman kumuh menjadi keharusan. UR melalui penataan kota yang lebih baik serta penanganan pemukiman kumuh dalam bentuk relokasi atau pemenuhan rumah bagi penduduk berpenghasilan rendah, setidaknya memiliki tujuan untuk menciptakan pengembangan masyarakat dalam hal penyediaan perumahan yang lebih baik dan menghindari akan adanya potensi-potensi terjadinya kriminalitas.

\section{DISKUSI: URBAN RENEWAL, SUATU PILIHAN ATAU KEHARUSAN}

Urban renewal diperlukan bagi perkotaan di Indonesia yang memprioritaskan kebijakan berorientasi menjadikan pusat kota sebagai area bisnis yang lebih kompetitif dan menghasilkan profit maksimal perkotaan melalui pemasukan pajaknya. Hal ini dilakukan melalui kebijakan pemerintah lokal dalam menentukan arah pengembangan kota. Di sisi lain, hal ini dilakukan untuk memperindah wajah kota yang akan dengan sendirinya meningkatkan pengembangan komunitas yang berada di kota maupun suburban.

Pembaruan kota dengan meningkatkan nilai jual land use perkotaan menimbulkan permasalahan tersendiri. Nilai jual lahan yang tinggi berdampak pada nilai sewa lahan yang tinggi, dimana hal ini tidak dapat dijangkau oleh masyarakat berpenghasilan rendah, hingga berakhir dengan inequity di komunitas perkotaan. Hak ini lebih kepada tuntutan kemajuan kota dan tidak dapat pula dipungkiri dengan adanya UR melalui pembenahan fasilitasfasilitas sosial, secara langsung juga mendatangkan manfaat bagi pengambangan masyarakat seluruh komunitas tanpa membeda-bedakan pemasukan ekonomi masingmasing individu.

Di sisi lain, urban renewal mengakibatkan tingginya harga pemukiman sehingga tidak terjangkau bagi warga berpenghasilan rendah, di sini timbul inequity, sehingga timbul jargon bahwa penduduk yang dapat tinggal di dekat pusat kota adalah penduduk yang miliki penghasilan menengah ke atas.

Pesatnya pertumbuhan ekonomi yang berdampak pada pengembangan kota-kota besar di Indonesia, menghadapi kasus yang cenderung menyerupai apa yang telah dihadapi Amerika Serikat di tahun 1949. Dari proyeksi populasi penduduk Indonesia tahun 2015-2045 didapatkan kondisi bahwa di tahun 2045 akan berlangsung bonus demografi, yakni jumlah penduduk usia kerja akan terus meningkat sehingga penduduk usia produktif lebih banyak dibanding penduduk usia non produktif. Angkatan kerja diproyeksikan akan tumbuh selama 30 tahun ke depan dengan laju tahunan sebesar 1,84 persen. Pada 2045, angkatan kerja diproyeksikan mencapai 206 juta jiwa. Pada tahun 2045, Indonesia akan mengalami pertumbuhan penduduk sebesar 63,4 juta atau 24,07 persen. Sekitar 67,1 persen penduduk akan tinggal di daerah perkotaan (Brodjonegoro, 2018). Meningkatnya pertumbuhan penduduk yang mana cenderung bertempat tinggal di perkotaan serta prediksi di tahun 2045 mencapai 318,9 juta jiwa, memerlukan penanganan serius tentang pengendalian pemukiman di wilayah perkotaan.

Dari catatan Direktorat Jenderal Cipta Karya Kementerian Pekerjaan Umum dan Perumahaan Rakyat (PUPR), di tahun 2017 jumlah penduduk miskin di perkotaan 
mencapai 10,49 juta, serta terdapat kawasan kumuh seluas 38.431 ha, backlog perumahan mencapai 7,6 juta rumah dan diperkirakan pada 2020 jumlah penduduk perkotaan akan mencapai 60\% (Novalius, 2017). Direktorat Jenderal (Ditjen) Cipta Karya Kementerian Pekerjaan Umum, Amwazi Idrus (Ariyanti, 2013; Zul \& Ang, 2013) menyampaikan bahwa dari 171 kawasan kumuh yang ditangani kementerian tersebut, terdapat lima kawasan slum area terparah (massive/ besar), diantaranya kawasan Kali Ciliwung (Jakarta), Belawan (Sumatera Utara) Taman Sari (Bandung), Boezem Morokembagan (Surabaya) dan Tallo (Makasar).

Kemajuan ekonomi dan pembangunan infrastruktur perkotaan tidak dapat dihentikan, namun dapat dikelola. Tergerusnya perumahan di tengah kota akibat ekspansi sektor ekonomi perkotaan sebagai dampak fenomena tersebut. Hal ini sering dijadikan alasan alih fungsi lahan pemukiman menjadi area yang lebih mendatangkan profit sektor perkotaan. UR adalah keharusan bagi perencanaan kota yang cenderung mengedepankan peningkatan aspek pertumbuhan ekonomi di pusat kota. Konsep idelnya adalah memadukan antara struktur ekonomi dan struktur perkotaan (physical planning and economic plannig) (Glasson, 1978; Glasson \& Marshall, 2007). Konsep UR memfokuskan pada struktur perkotaan yang berorientasi struktur ekonomi untuk mengoptimalisasikan fungsi land use di perkotaan.

Kemajuan ekonomi meningkatkan urbanisasi menuju pusat kota serta pertumbuhan penduduk yang berujung dengan padatnya pemukiman, berkembangnya slum area dan minimnya pelayanan dasar publik. Di sisi lain, juga ditengarai oleh tidak terjadinya urban sprawl akibat incom rendah warga slum area. Urban renewal perlu diimbangi dengan pemenuhan pemukiman yang layak huni bagi ex penduduk slum area. Hal ini dilakukan untuk menyeimbangkan antara aktifitas ekonomi dan sosial di perkotaan.

Konsep UR melalui pertumbuhan bangunan kumuh yang berada di pusat kota untuk selanjutnya menggantinya dengan bangunan baru yang lebih mengedepankan sektor profit adalah proses yang kompleks dan memerlukan integrasi antar berbagai pihak (khususnya dalam penyediaan anggaran untuk akuisisi lahan). Kebijakan pengembangan kawasan perkotaan di Indonesia terdiri dari beberapa hirarki diantaranya kebijakan pusat, provinsi dan daerah. Peran pemerintah daerah, dalam hal ini pemerintah kota sangat strategis untuk menentukan kemajuan perkotaan. Penanganan perencanaan kota cenderung sangat sensitif dengan kerifan lokal kota tersebut. Batasan urban renewal di perkotaan Indonesia adalah kearifan lokal dalam konteks kebijakan basis pengembangan kota. Gagasan ini akan menentukan arah kebijakan kemajuan pusat kota apakah di tata saat ini atau dibiarkan terus menerus hingga mencapai suatu keadaan pusat kota yang dipenuhi oleh slum area. Penanganan slum area mendatangkan manfaat yang lebih besar kepada keberlangsungan perekonomian kota dan pengembangan masyarakat.

Pembaruan kota di Indonesia harus didampingi oleh pemukiman layak huni yang mendukung keindahan kota. Artikel ini memandang ada dua opsi perencanaan kota di indonesia, yang berbasis orientasi ekonomi atau berbasis orientasi keseimbangan antara ekonomi dan hunian. Bagi orientasi ekonomi, maka pusat kota dikondisikan sedemikian rupa menjadi area yang dipenuhi oleh bangunan-bangunan yang mendatangkan pajak besar bagi kota, seperti ritel, perkantoran, taman kota serta hunian real estate atau apartemen yang mendukung keindahan kota. Bagi perencanaan kota yang berbasis orientasi keseimbangan maka dilakukan melalui penataan kampung kota dan keseimbangan bangunan di sekitarnya. Pemukiman di pusat kota cenderung diupayakan seindah mungkin agar mempercantik wajah kota. Dalam konteks UR, kosep ini akan meningkatkan kualitas pengembangan masyarakat.

Pembaruan perkotaan yang dipimpin oleh pemerintah tidak selalu mengarah pada eksternalitas positif, seperti yang diharapkan (Lai, Chau, \& Cheung, 2018, hlm. 240). Sebagai mana contoh kasus pembangunan Pruitt-Igoe (1956) dengan kondisi yang sangat 
bagus, namun di tahun 1971 kondisi berubah menjadi bangunan yang tidak terawat yang berakhir pada penghancuran perumahan publik tersebut. Kasus Pruitt-Igoe adalah pembangunan perumahan sebagai tempat tujuan relokasi warga slum area yang belum mampu mengatasi masalah kota. Hal ini ditengarai oleh dinamika sosial, ekonomi dan politik. Penanganan bagi pemukiman kumuh yang dilakukan dalam bentuk relokasi menuju bangunan yang lebih layak seperti rumah susun juga harus benar-benar memperhatikan aspek pengelolaan rumah susun tesebut, khususnya intensitas dinamika yang terjadi dalam pemanfaatannya. Urbanisasi yang cepat dan tidak terencana akan mengarah pada kualitas hidup yang buruk tanpa pertumbuhan ekonomi yang tepat sehingga menodai trajektori pertumbuhan bangsa. Oleh karena itu, menjadi tugas utama untuk mengembangkan daerah perkotaan dengan memasang kerangka penelitian yang layak dan layak (Manupati, Ramkumar, \& Samanta, 2018, hlm. 480). Sehingga dengan demikian diperlukan adanya keselarasan bagi kebiakan yang telah dijalankan, khususnya dalam pengelolaan perumahan tujuan relokasi warga pemukiman kumuh tersebu.

\section{KESIMPULAN}

Urban renewal perlu dilakukan untuk perkotaan di Indonesia bagi kebijakan yang berorientasi tujuan menjadikan pusat kota sebagai area bisnis yang lebih kompetitif dan menghasilkan profit maksimal perkotaan dengan pemasukan pajaknya. Di sisi lain, hal ini dilakukan untuk memperindah wajah kota yang akan dengan sendirinya meningkatkan pengembangan komunitas yang berada di kota maupun suburban, serta kearifan lokal menjadi batasan urban renewal.

Urban renewal memberikan peluang bangi kelangsungan pengembangan manusia yang lebih baik karena penataan lingkungan perkotaan yang lebih terarah dan lebih humanis. Di sisi lain, urban renewal mengakibatkan tingginya harga pemukiman sehingga tidak terjangkau bagi warga berpenghasilan rendah, di sini timbul inequity, sehingga timbul jargon bahwa penduduk yang dapat tinggal di dekat pusat kota adalah penduduk yang miliki penghasilan menengah ke atas. Namun, di sisi lain ini adalah tuntutan kemajuan perkotaan dimana pusat kota dijadikan sebagai incom perkotaan. Sehingga diperlukan adanya keselarasan antara pemukiman yang baik dan tertata di suburban.

\section{DAFTAR PUSTAKA}

Adams, D., \& Hastings, E. M. (2001). Urban renewal in Hong Kong: transition from development corporation to renewal authority. Land Use Policy, 18(3), 245-258.

Adnan, M. N., Safeer, R., \& Rashid, A. (2018). Consumption based approach of carbon footprint analysis in urban slum and non-slum areas of Rawalpindi. Habitat International, 73, 16-24.

Alam, M. S., \& Mondal, M. (2018). Assessment of sanitation service quality in urban slums of Khulna City based on SERVQUAL and AHP model: a case study of railway slum, Khulna, Bangladesh. Journal of Urban Management.

Ariyanti, F. (2013). Yuk intip, 5 kawasan kumuh terparah di Indonesia. Diambil 24 September 2018, dari https://www.liputan6.com/bisnis/read/687844/yuk-intip-5-kawasan-kumuh-terparah-di-indonesia.

Brodjonegoro, B. P. S. (2018). Sustainable urban development in Jabodetabek. Dipresentasikan pada The 6th International Conference of Jabodetabek Study Forum, Bogor.

Chan, E. H. W., \& Yung, E. H. K. (2004). Is the development control legal framework conducive to a sustainable dense urban development in Hong Kong? Habitat International, 28(3), 409-426.

Glasson, J. (1978). An introduction to regional planning: concepts, theory and practice. Hutchinson.

Glasson, J., \& Marshall, T. (2007). Regional Planning. Taylor \& Francis.

Lai, L. W. C., Chau, K. W., \& Cheung, P. A. C. W. (2018). Urban renewal and redevelopment: social justice and property rights with reference to Hong Kong's constitutional capitalism. Cities, 74, 240-248.

Lee, G. K. L., \& Chan, E. H. W. (2008). The analytic hierarchy process (AHP) approach for assessment of urban renewal proposals. Social Indicators Research, 89(1), 155-168.

LeGates, R. T., \& Stout, F. (2015). The city reader (Sixth Edition). New York: Routledge.

Levy, J. M. (2016). Contemporary urban planning (11th Edition). New York: Routledge. 
Manupati, V. K., Ramkumar, M., \& Samanta, D. (2018). A multi-criteria decision making approach for the urban renewal in Southern India. Sustainable Cities and Society, 42, 471-481.

Montgomery, M. R., Stren, R., Cohen, B., \& Reed, H. E. (2013). Cities transformed: demographic change and Its implications in the developing world. Washington, D.C.: Routledge.

Novalius, F. (2017). Masih ada 90\% kawasan kumuh di Indonesia, Kementerian PUPR: masalahnya komunikasi tidak lancar! Diambil $24 \quad$ September 2018, dari https://economy.okezone.com/read/2017/09/05/470/1769577/masih-ada-90-kawasan-kumuh-diindonesia-kementerian-pupr-masalahnya-komunikasi-tidak-lancar.

Reason TV. (2011). The tragedy of urban renewal: the destruction and survival of a New York City neighborhood. Diambil 14 Oktober 2018, dari https://www.youtube.com/watch?v=mWGwsA1V2r4.

Wang, Y., Li, J., Zhang, G., Li, Y., \& Asare, M. H. (2017). Fuzzy evaluation of comprehensive benefit in urban renewal based on the perspective of core stakeholders. Habitat International, 66, 163-170.

Wankhade, K. (2015). Urban sanitation in India: key shifts in the national policy frame. Environment and Urbanization, 27(2), 555-572.

Zheng, H. W., Shen, G. Q., \& Wang, H. (2014). A review of recent studies on sustainable urban renewal. Habitat International, 41, 272-279.

Zul, \& Ang. (2013). Ini penampakan 5 kawasan paling kumuh di Indonesia. Diambil 15 Oktober 2018, dari https://finance.detik.com/berita-ekonomi-bisnis/d-2355224/ini-penampakan-5-kawasan-palingkumuh-di-indonesia. 